\title{
X-RAY TOPOGRAPHIC OBSERVATIONS OF EDGE DISLOCATION GLIDE ON NON-BASAL PLANES IN ICE
}

\author{
By C. SHEARWOOD and R.W. WHITWORTH
}

(School of Physics and Space Research, University of Birmingham, Birmingham B15 2TT, England)

ABSTRACT. White synchrotron X-radiation topography has been used to observe the motion of dislocations in single crystals of ice under a compressive stress in the [1100] direction, for which there is no resolved stress on the basal plane. Dislocations with $[1 \overline{2} 10]$ and $[\overline{2} 110]$ Burgers vectors were nucleated from surface scratches, and their edge components were observed to glide on non-basal planes, which may be prismatic or may have unspecific pyramidal character. Screw components are not mobile on such planes.

\section{INTRODUCTION}

$\mathrm{X}$-ray topography has been extensively used to study dislocations in crystals of ice (Higashi, 1988). In recent years, the power of the technique has been greatly enhanced by the use of $\mathrm{X}$-rays from a synchrotron radiation source, and Ahmad and others (1987) and Ahmad and Whitworth (1988) have reported sequences of topographs showing the motion and multiplication of dislocations under an applied stress. One observation described in these papers is that short segments of dislocation with $\langle 11 \overline{2} 0\rangle$ Burgers vector in edge orientation glide on non-basal planes with a velocity an order of magnitude greater than that of screw or $60^{\circ}$ segments on the basal plane. This behaviour, which has also been reported by Higashi and others (1985), is remarkable because it is very difficult to produce macroscopic slip in

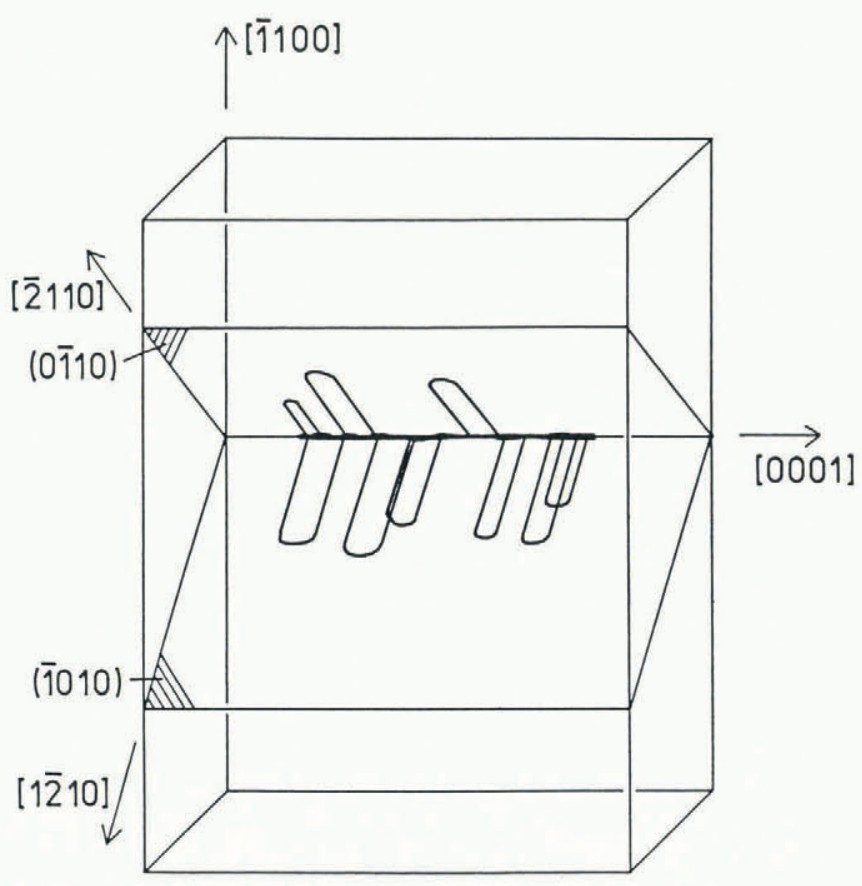

Fig. 1. Diagram showing orientation of the specimens and the dislocation loops formed from a horizontal scratch on the back face as seen in Figure 2. ice on any plane other than the basal plane (Higashi, 1967; Duval and others, 1983). Nevertheless, non-basal slip plays an important role in deformation because it provides the principal mechanism for the generation of the dislocations which subsequently produce macroscopic basal slip.

This paper describes further X-ray topographic experiments carried out to study non-basal dislocation glide in specimens oriented so that basal slip cannot occur.

\section{EXPERIMENTAL DETAILS}

Crystals of ice were grown by the method of Ohtomo and others (1987) and cut to form specimens with dimensions $20 \mathrm{~mm} \times 12 \mathrm{~mm} \times 1.5 \mathrm{~mm}$ in the orientation shown in Figure 1. White radiation $\mathrm{X}$-ray topographic experiments were carried out using the synchrotron radiation source at the S.E.R.C. Daresbury Laboratory as described by Ahmad and Whitworth (1988). In the experiments reported here, the diffraction vector was [1 $1 \overline{1} 00]$ with a Bragg angle of $6.5^{\circ}$. The beam was incident approximately perpendicular to the back face of the specimen as seen in Figure 1, and all topographs except Figure $4 \mathrm{~b}$ show the specimen as if looking directly at the front face.

The specimens used had a relatively low initial dislocation density, and those dislocations that were present were confined mainly to the basal planes which are seen edge-on in the orientation described, so that these dislocations appear as vertical lines. The orientation is chosen so that under a compressive stress along the vertical [1100] direction there is no resolved stress on the basal plane. Under compressive loads of up to $3 \mathrm{~kg}$ the specimens as mounted showed no noticeable dislocation motion.

Fresh dislocations were introduced into the specimens by scratching the back face, and sequences of topographs were obtained showing the dislocations after successive applications of loads of 1 or $2 \mathrm{~kg}$ for periods of 0.5 or $1 \mathrm{~min}$ at $-15^{\circ} \mathrm{C}$.

\section{OBSERVATIONS}

The topographs in Figure 2 show the propagation of dislocations from a horizontal scratch. The dislocation loops are expanding on the (1010) and (0 $\overline{1} 10)$ planes as illustrated in Figure 1; the three-dimensional character is not clear from this figure alone but will be justified later. The segments moving away from the scratch are edge dislocations and those running vertically in the figure are screw dislocations. Continuation of the stressing beyond the last topograph in Figure 2 results eventually in the edge segments moving out of the front face of the specimen, leaving only screw dislocations running between the front and back faces. Careful examination of the topographs shown and similar ones of this and other specimens has revealed no widening of the loops such as would result from the glide of the screw segments on the $\{\overline{1010}\}$ planes. The mean velocity of the edge dislocations on their slip plane in this specimen is about $4.3 \mu \mathrm{m} \mathrm{s}^{-1}$ for a resolved shear stress of $0.48 \mathrm{MPa}$. 

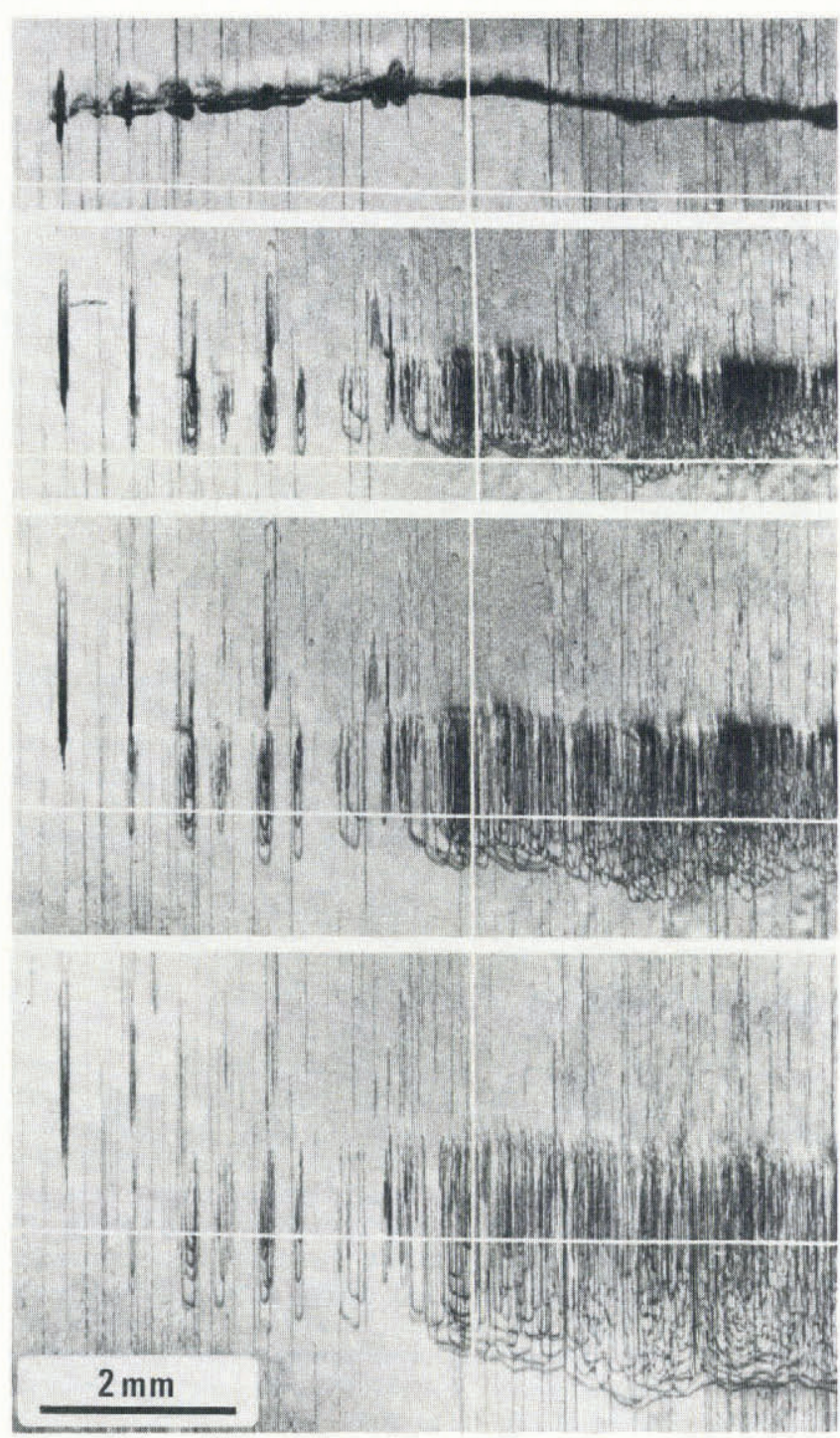

Fig. 2. Topographs showing a horizontal scratch and the dislocation loops propagating from it after 3, 5, and $9 \mathrm{~min}$ under vertical compressive stress of $1.1 \mathrm{MPa}$ at $-15^{\circ} \mathrm{C}$. The white lines are cross wires in front of the crystal.

Figure 3 is a single topograph at higher magnification showing dislocations which have propagated from a diagonal scratch. Many of the loops are wide and must terminate on the surface at points with differing heights. The edge segments of such loops cannot lie on single (1010) planes; their planes must have a pyramidal character but need not have a simple crystallographic orientation.

Figure 4 shows a pair of topographs of another specimen in which dislocations have propagated from a diagonal scratch. In Figure $4 \mathrm{a}$ the specimen is viewed as in the two previous examples, but in Figure $4 \mathrm{~b}$ it has been rotated through $30^{\circ}$ about a vertical axis. In this view, preexisting dislocations on the basal plane can be seen running from the front to the back of the specimen and it is clear that the dislocations propagating from the scratch lie in a plane containing both the $[1 \overline{2} 10]$ direction and the line of the scratch. In this specimen some of the dislocations, particularly to the lower right, can be seen to have run right through the specimen. The velocity of the dislocations in the main band is about $20 \mu \mathrm{m} \mathrm{s}^{-1}$, which is four times faster than in the case of Figure 2.

\section{DISCUSSION}

These experiments provide confirmation of the idea developed by Ahmad and Whitworth (1988) that edge, but

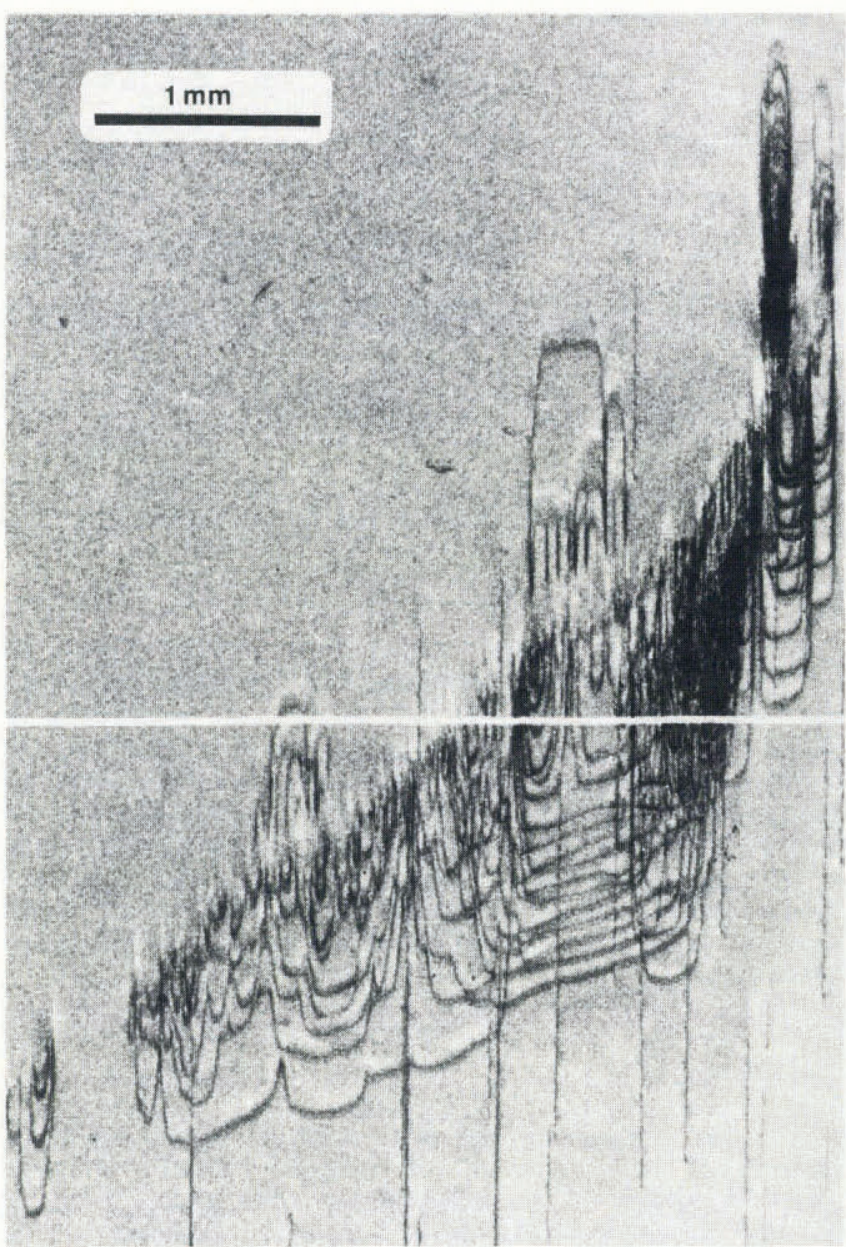

Fig. 3. Topograph of dislocations formed from a diagonal scratch after $6 \mathrm{~min}$ under compressive stress of $0.55 \mathrm{MPa}$ at $-15^{\circ} \mathrm{C}$

not screw, dislocations with the usual $\langle 11 \overline{2} 0\rangle$ basal Burgers vector can glide easily on non-basal planes containing their Burgers vector. The observations in that paper of the fastmoving tips of long loops had to be accounted for by slip on pyramidal planes such as $\{1 \overline{1} 01\}$ or $\{1 \overline{102}\}$. The present observations in Figure 2 show that the prismatic plane is also a possible glide plane, although in Figures 3 and 4 the glide plane for many of the dislocations has to have pyramidal character. On a macroscopic scale, almost any plane between $\{1 \overline{1} 00\}$ and $\{1 \overline{1} 02\}$ appears to be possible, but one cannot tell from experiments at this resolution whether the dislocations observed are made up of components on two or more specific low index planes.

Dislocation velocities for non-basal glide at $-15^{\circ} \mathrm{C}$ ranged from 4.3 to $20 \mu \mathrm{m} \mathrm{s}^{-1}$ at a resolved stress on the prismatic plane of $0.43 \mathrm{MPa}$. Ahmad and Whitworth (1988) studied the motion of the short non-basal segments that formed the tips of long loops in specimens oriented for slip on the basal plane, and obtained velocities of $2.5-5.8 \mu \mathrm{m} \mathrm{s}^{-1}$ at $-10^{\circ} \mathrm{C}$ under a resolved shear stress on the basal plane of $0.1 \mathrm{MPa}$. For comparable stresses and temperatures, these velocities would be similar in magnitude and faster than straight segments on the basal plane.

The reason that macroscopic non-basal slip is so difficult is that the screw dislocations do not glide on these planes, and this prevents whole loops expanding or multiplication occurring on them. The reason for the immobility of the screw dislocations on non-basal planes is likely to be that they are dissociated into partial dislocations on the basal plane as proposed by Higashi and others (1985). However, they claimed that this dissociation is the reason for the relatively low mobility of edge dislocations on basal planes, whereas we use it to explain the immobility of screw dislocations on non-basal planes. We offer no further discussion of the theory of dislocation velocities than that contained in Ahmad and Whitworth (1988). 


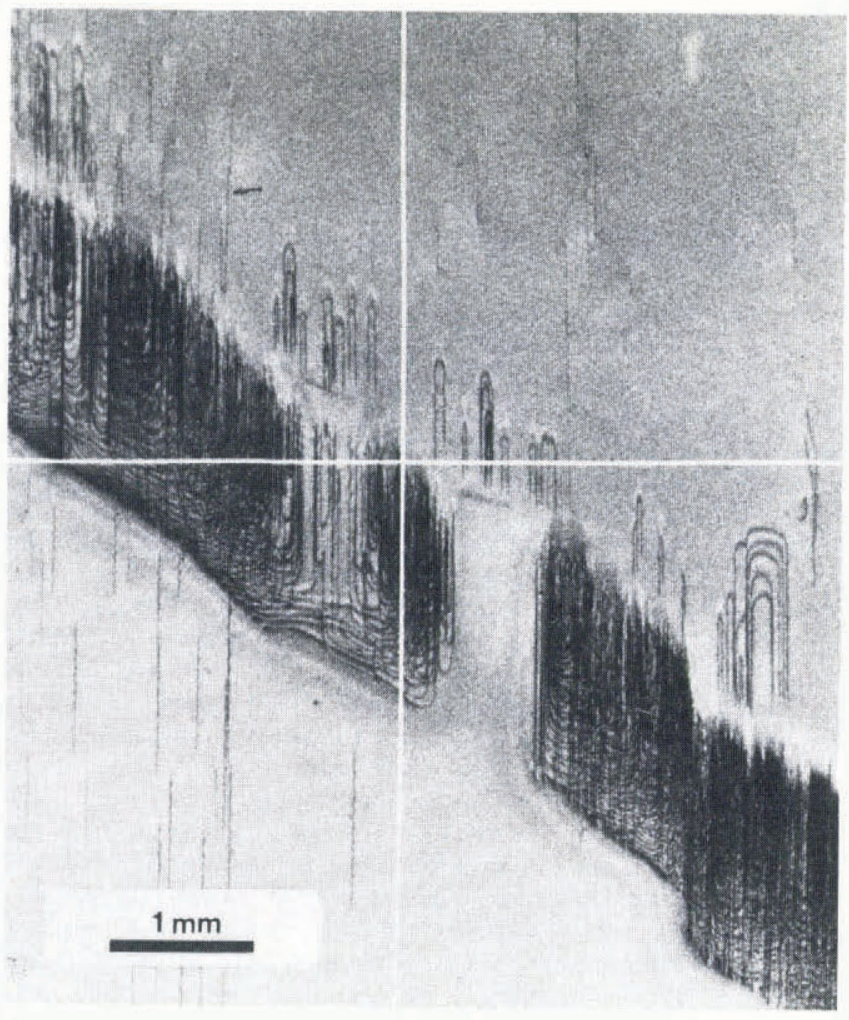

a

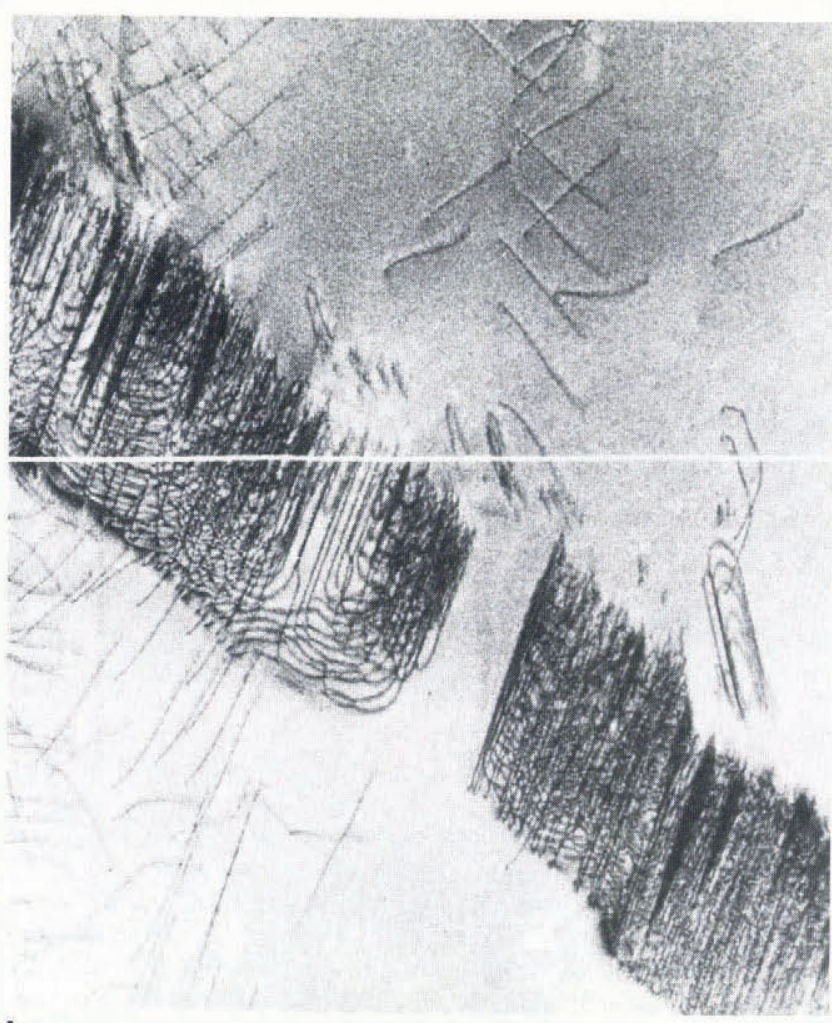

b

Fig. 4. Topographs of dislocations formed from a diagonal scratch after 3 min under compressive stres. of $1.1 \mathrm{MPa}$ at $-15^{\circ} \mathrm{C}$. (a) View perpendicular to the face of the specimen. (b) View with specimen rotated through $30^{\circ}$ about the vertical axis.

\section{ACKNOWLEDGEMENTS}

This work was supported by a research grant from the U.K. Science and Engineering Research Council, and we are grateful for the use of the facilities at the Daresbury Laboratory. We thank Dr G.F. Clark and Dr R. Howe for valuable assistance.

\section{REFERENCES}

Ahmad, S. and R.W. Whitworth. 1988. Dislocation motion in ice: a study by synchrotron X-ray topography. Philos. Mag., Ser. A, 57(5), 749-766.

Ahmad, S., M. Ohtomo, and R.W. Whitworth. 1987. The study of dislocation glide in ice by synchrotron radiation X-ray topography. J. Phys. (Paris), 48, Colloq. C1, 175-181. (Supplëment au 3.)

Duval, P., M.F. Ashby, and I. Anderman. 1983. Ratecontrolling processes in the creep of polycrystalline ice. $J$. Phys. Chem., 87(21), 4066-4074.
Higashi, A. 1967. Mechanisms of plastic deformation in ice single crystals. In Öura, H., ed. Physics of Snow and Ice. International Conference on Low Temperature Science ... 1966 ...Proceedings, Vol. 1, Pt. I. Sapporo, Hokkaido University. Institute of Low Temperature Science, 277-289.

Higashi, A. 1988. Lattice defects in ice crystals - X-ray topographic observations. Sapporo, Hokkaido University Press.

Higashi, A., A. Fukuda, T. Hondoh, K. Goto, and S. Amakai. 1985. Dynamical dislocation processes in ice crystal. In Suzuki, H., T. Ninomiya, K. Sumino, and S. Takeuchi, eds. Dislocations in Solids. Proceedings Yamada Conference IX, Tokyo, 1984. Tokyo, University of Tokyo Press, 511-515.

Ohtomo, M., S. Ahmad, and R.W. Whitworth. 1987. A technique for the growth of high quality single crystals of ice. J. Phys (Paris), 48, Collog. C1, 595-598. (Supplèment au 3.) 